\title{
520 Press forming of high tensile strength steel sheet - Hat channel product combined straight part with curved part in longitudinal direction-
}

\author{
Takahiro Iyama*, Takashi Hoshi*, Kentaro Odanaka**, Yoshio Fujishiro*** \\ Motoo Asakawa*, Ikuhiko Hayashi*, \\ *Department of Mechanical and Engineering, Waseda University \\ 3-4-1 Ookubo, Shinjuku-ku, Tokyo 169-8555, Japan \\ **Graduate student \\ ***Unipres corporation
}

\begin{abstract}
This paper deals with the complexly-shaped hat channel product, which combines a straight part with a curved part in the longitudinal direction. Twist in the longitudinal direction is the most typical and serious of all dimensional inaccuracies in the product. Influencing factors in twisting can be classified into residual stress and residual moment. At first by varying forming conditions, such as blank holding force and cushion force, the influence of the residual stress generated on shrink and stretch flange on twist are investigated. Contrary to our expectation, the residual stress had almost no relation to twist. Subsequently, by cutting flanges and side wall to release the residual moment, the influence of the residual moment on twist was investigated. It was observed that the residual moment plays an important role on twist. Based on the above, some parts of die radius are varied to control residual moment. As a result, it is experimentally found that twist decreased.
\end{abstract}

Key Words: Press Forming, High Tensile Strength Steel sheet, Hat Channel, Twist in the Longitudinal Direction

\section{INTRODUCTION}

Lightness and high rigidity are required for automotive body structure. To achieve these requires, high tensile strength steel sheet is used for car reinforcement parts. But, processing high tensile strength steel sheet becomes more difficult as its strength is rased, and the dimensional inaccuracies of product cause trouble, such as spring back [1].

This paper deals with hat channel product, a product which combines a straight part with a curved part in the longitudinal direction. Twist in longitudinal direction is the most typical and serious of dimensional inaccuracies.

Generally, influencing factors on twist in the longitudinal direction can be classified into residual stress and residual moment. It can be considered that the residual stress acts to create twist in the longitudinal direction in materials such as hat product made of thin sheet [2]. However, the sheet used in this study is not thin. Hence, there is need to consider how the residual moment acts on twist in the longitudinal direction. By varying forming conditions, the mechanism of occurring twist in the longitudinal direction is investigated. Moreover, the strategy to decrease twist in the forming process is examined.

\section{OUTLINE OF EXPERIMENT}

\subsection{Material and product shape}

$60 \mathrm{kgf}$ class high tensile strength steel sheet (Dual Phase) is used. Material properties are shown in Table1. Thickness is $1.6 \mathrm{~mm}$. And other dimensions are shown in Fig.1(a). Three kinds of product are shown in Fig.1(b), (c),and(d) which shows a straight part, a curved part, and combined product which has both straight part and curved part.

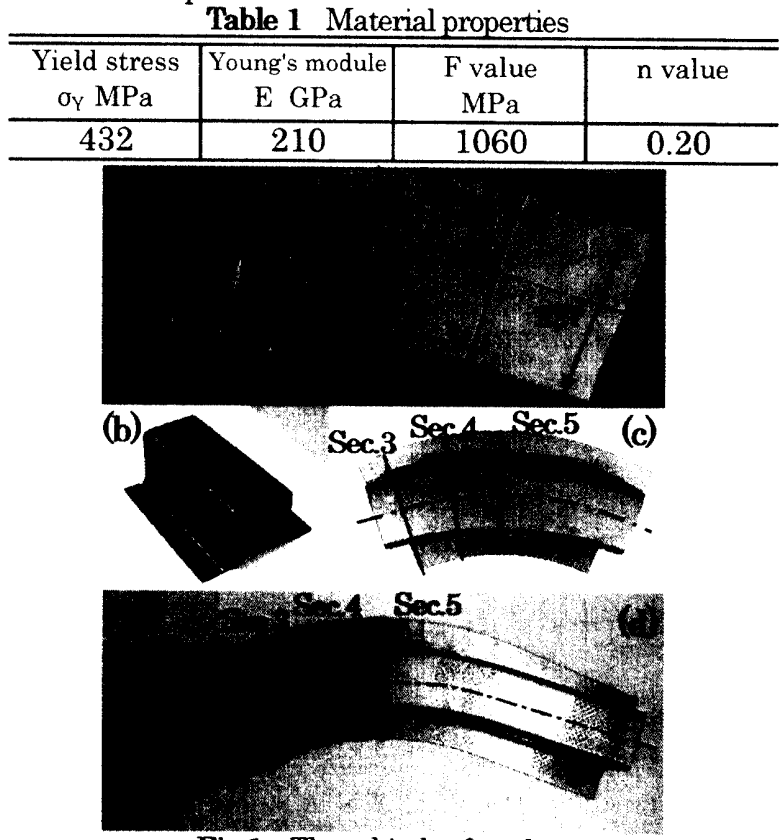

Fig.1 Three kinds of product 


\subsection{Forming conditions}

A hydraulic press machine was used for forming. Punch velocity was $12 \mathrm{~mm} / \mathrm{s}$. Forming conditions are shown in Table2. Punch force was $2500 \mathrm{kN}$, blank holding force was $150,450 \mathrm{kN}$, and cushion force was 30 , $500 \mathrm{kN}$. Outside die radius (called shrink side) and inside die radius (called stretch side) was $6 \mathrm{~mm}$, punch radius was set at $6 \mathrm{~mm}$. Clearance ratio was set at 1.1, which is ratio of between die and punch and thickness.

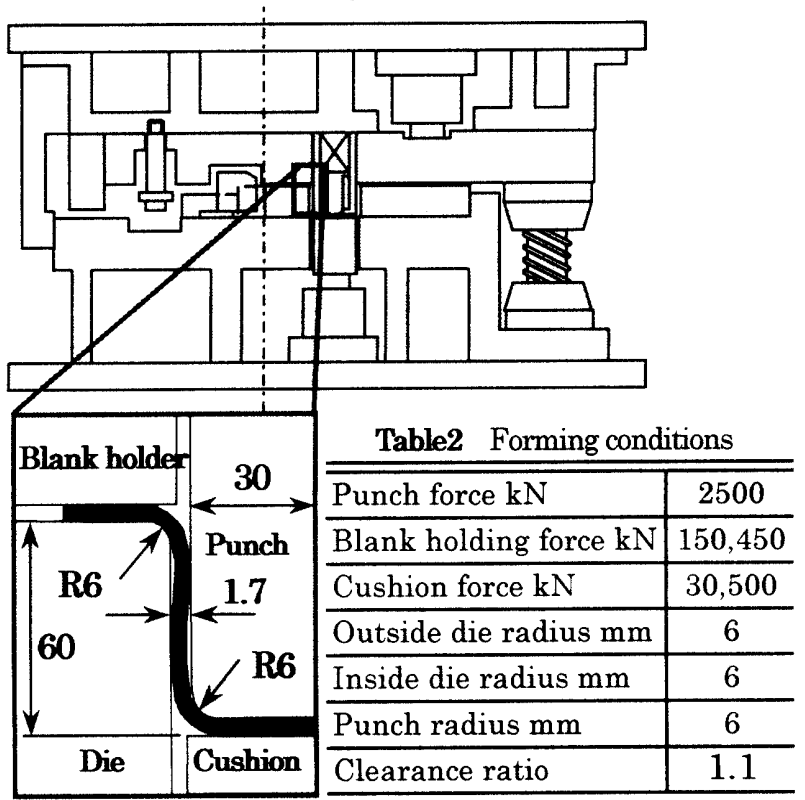

Fig.2 Forming apparatus

\subsection{Measurement method}

Curvature of side wall shown in Fig.3 was measured using contour measuring instruments. Curvature $1 / \rho$ was calculated by circular arc approximation from measured date. Twist in the longitudinal direction shown in Fig.3 was measured, using a three-dimensional coordinate measuring machine. Twist angle $\phi$ was defined as the angle at each section with section 5 .

The nominal strain distribution in section 5 was calculated from the interval of the marking line, using strain measurement film. Interval of marking line is 5 $\mathrm{mm}$ at straight part, and 1 degree at curved part. It is measured at on interval of $10 \mathrm{~mm}$, as shown in Fig.4.

Center position moved during the forming, as shown in Fig.5. Therefore flanges did not deform uniformly. Hence, movement of centerline was examined and when centerline moved toward shrink side, it was defined positive, and when stretch side, negative.

\section{RESULT OF EXXPERIMENT}

\subsection{Influence of blank holding force (BHF)}

By varying blank holding force (BHF) under constant cushion force (CF) of $30 \mathrm{kN}$, the influence of the

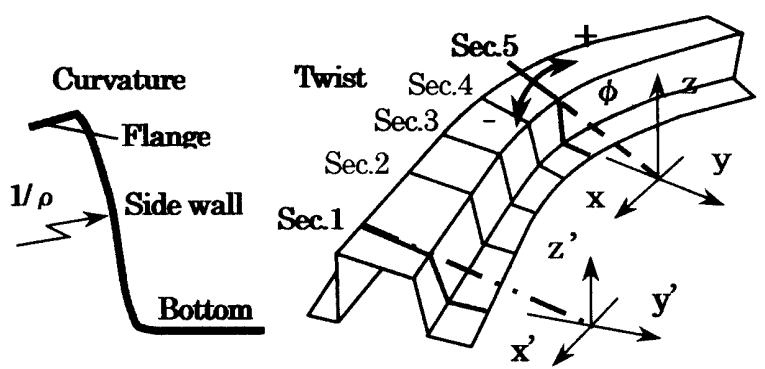

Fig. 3 Measurement index

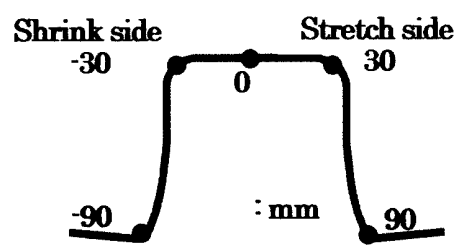

Fig.4 Measurement point

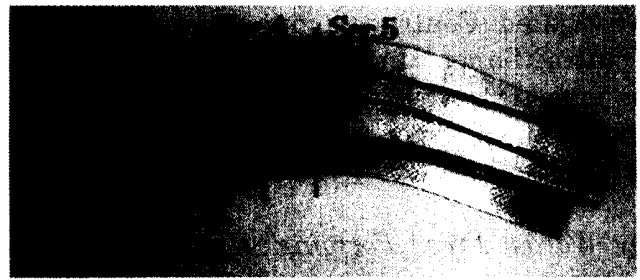

Fig.5 Movement of center position

residual stress generated on shrink and stretch flange on the curvature on side wall, movement of centerline, and twist was investigated.

Fig.6 shows the variation of the movement of the centerline. Under BHF of $150 \mathrm{kN}$, about $5.5 \mathrm{~mm}$ of movement of centerline occurs in section 5 , and, on the other hand, about $-5 \mathrm{~mm}$ of movement of centerline occurs in section 1 . Only small difference was observed when BHF was modified to $450 \mathrm{kN}$, compared to that with BHF of $150 \mathrm{kN}$.

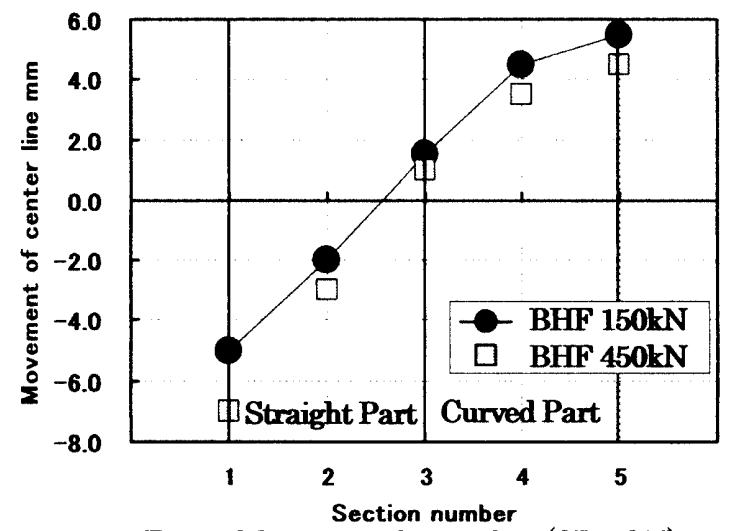

Fig.6 Movement of center line (CF $30 \mathrm{kN})$ 


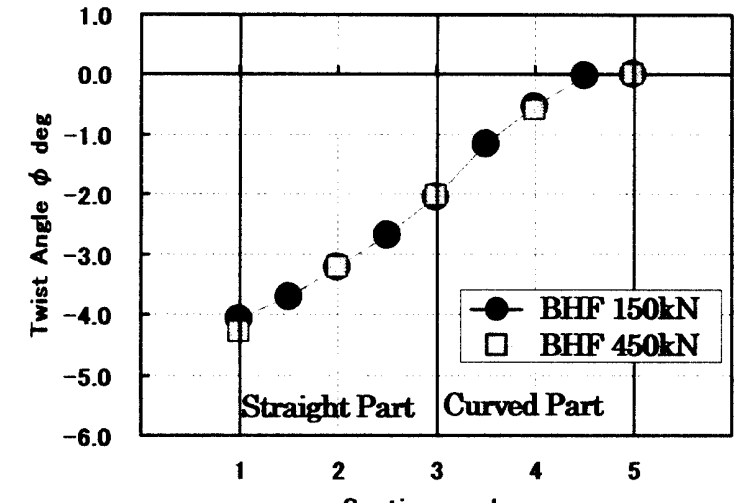

Fig.7 Distribution of twist (CF $30 \mathrm{kN})$

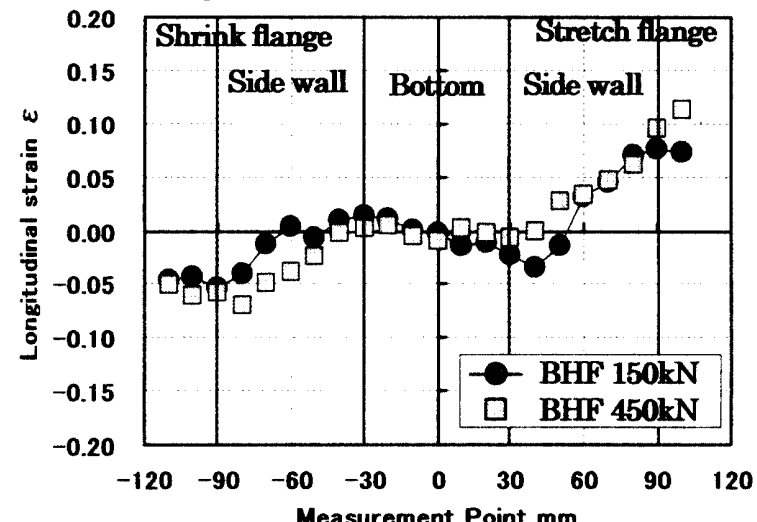

Fig.8 Distribution of strain in section $5(\mathrm{CF} 30 \mathrm{kN})$

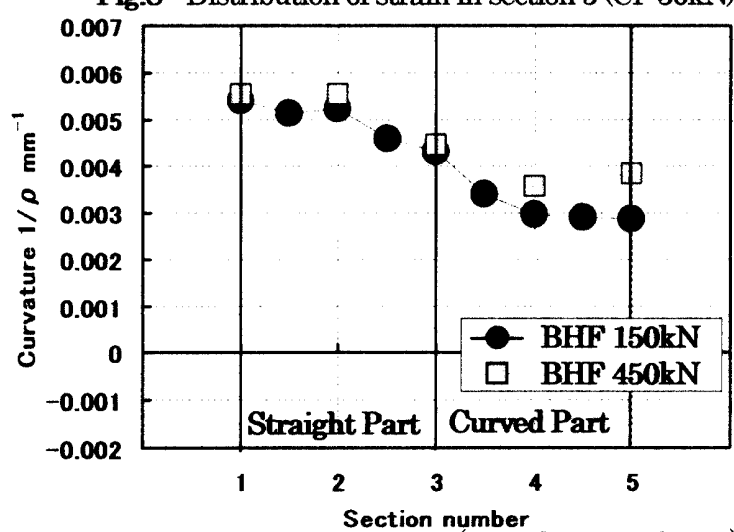

Fig.9 Distribution of curvature (CF $30 \mathrm{kN}$, shrink side)

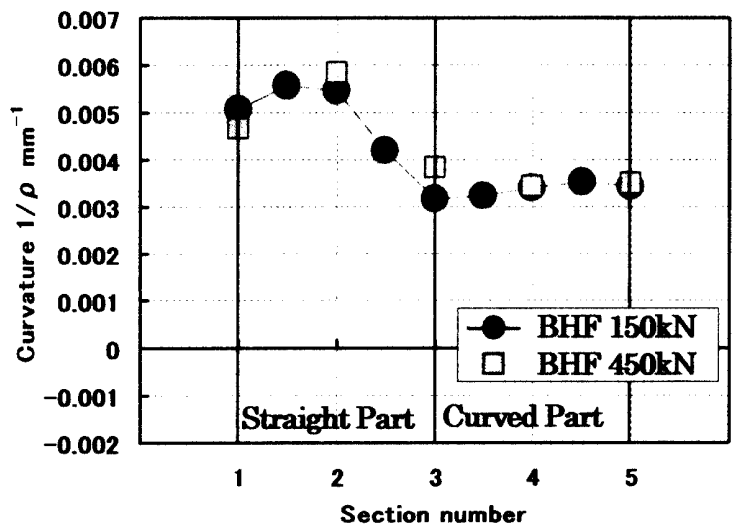

Fig.10 Distribution of curvature (CF $30 \mathrm{kN}$, stretch side)
Fig.7 shows the variation of twist, 4 degrees of twist direction in section 1 oocurs at both BHF of $150 \mathrm{kN}$ and $450 \mathrm{kN}$. The two results are almost identical.

Fig. 8 shows the variation of longitudinal strain, under $\mathrm{BHF}$ of $150 \mathrm{kN}$, about $5 \%$ longitudinal strain on shrink flange occurs. As it approaches from flange to bottom center, the absolute value of the strain decreased. On the other hand, $7 \%$ of longitudinal strain on stretch flange occurs. And the same remark as the stretch side can be made. Under BHF of $450 \mathrm{kN}$, relatively about $3 \%$ of longitudinal strain on shrink side increased compared to that with $\mathrm{BHF}$ of $150 \mathrm{kN}$, and relatively about $5 \%$ of longitudinal strain on stretch flange increased compared to that with $\mathrm{BHF}$ of $150 \mathrm{kN}$.

Fig.9, and Fig10 shows the variation of curvature, under BHF of $150 \mathrm{kN}$, about $0.005 \mathrm{~mm}^{-1}$ of curvature in section 1 occurs, and about $0.003 \mathrm{~mm}^{-1}$ of curvature in section 5 occurs. Under BHF of $450 \mathrm{kN}$, curvature does not vary relatively.

The results obtained in this section can be summarized that, under the higher BHF of $450 \mathrm{kN}$, the amount of longitudinal strain increased. However, twist did not vary relatively. Hence, the blank holding force had almost no relation to twist.

\subsection{Influence of cushion force (CF)}

By varying cushion force (CF) under constant blank holding force $(\mathrm{BHF})$ of $150 \mathrm{kN}$, the influence of the residual stress generated on shrink and stretch flange on the curvature on side wall, movement of centerline, and twist was investigated.

At first, Fig.11 shows the variation of movement of centerline, under $\mathrm{CF}$ of $30 \mathrm{kN}$, about $5.5 \mathrm{~mm}$ of movement of centerline in section 5 occurs on the shrink side, and on the other hand, about $5 \mathrm{~mm}$ of movement of centerline in section 1 occurs on the stretch side.

When CF is modified to $500 \mathrm{kN}$, movement of centerline on all sections is hardly seen.

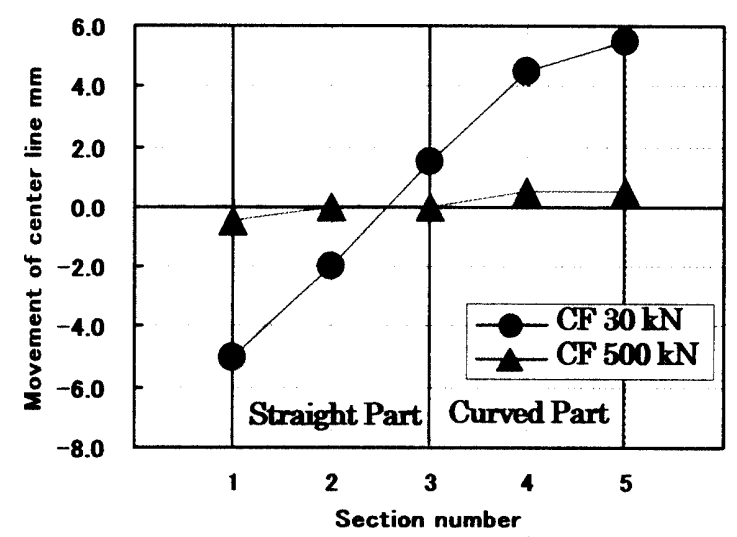

Fig.11 Movement of centerline (BHF $150 \mathrm{kN}$ ) 


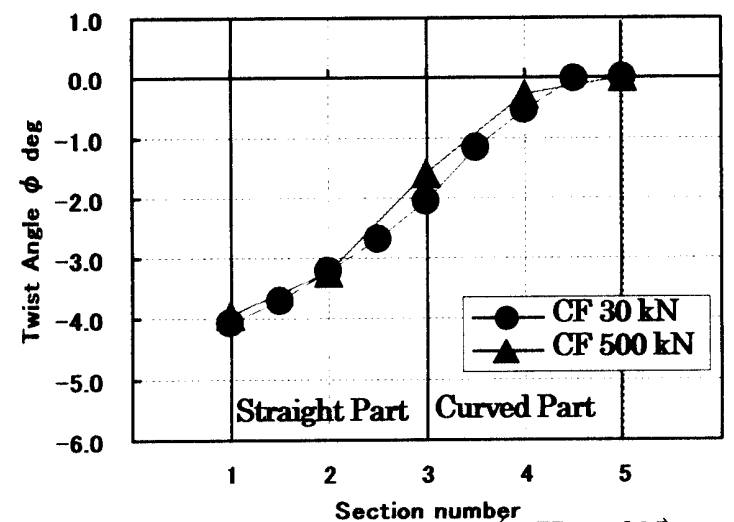

Fig.12 Distribution of twist (BHF $150 \mathrm{kN}$ )

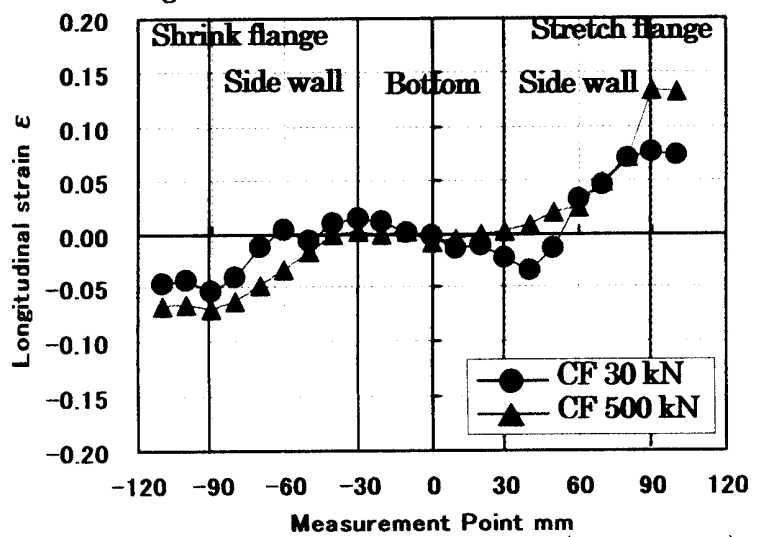

Fig.13 Distribution of strain in section 5 (BHF $150 \mathrm{kN}$ )

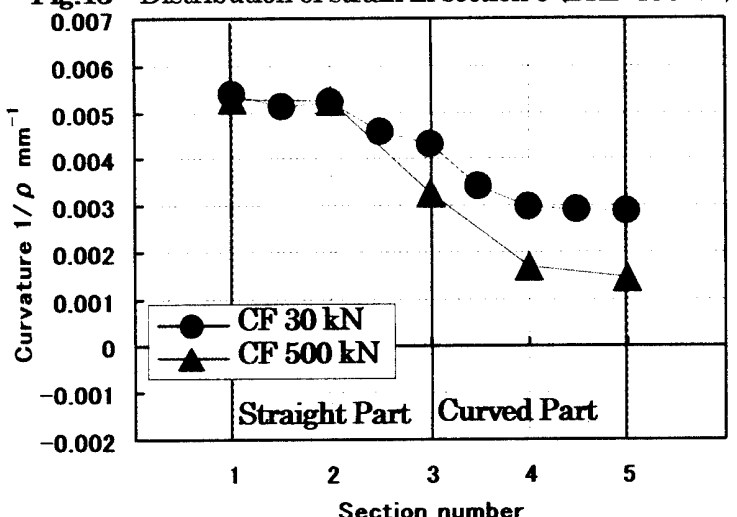

Fig.14 Distribution of curvature (BHF $150 \mathrm{kN}$, shrink side)

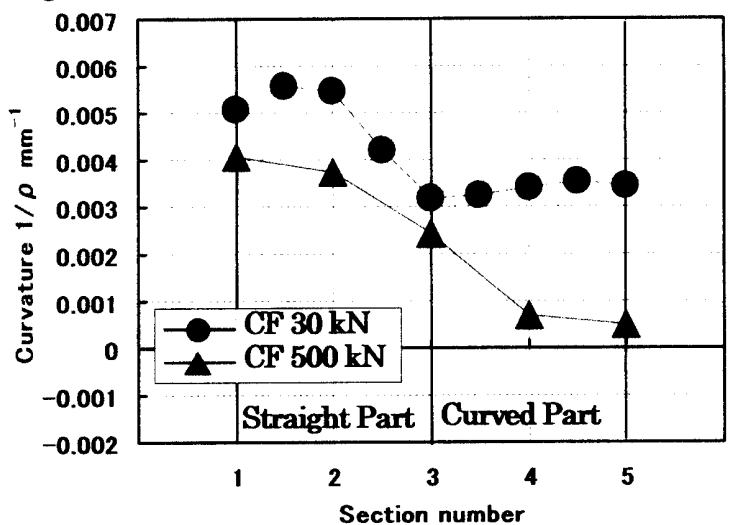

Fig.15 Distribution of curvature (BHF $150 \mathrm{kN}$, stretch side)
Fig.12 shows the variation of twist, 4 degrees of twist in section 1 occurs both $\mathrm{CF}$ of $30 \mathrm{kN}$ and $500 \mathrm{kN}$. The two results are almost identical.

Fig.13 shows the variation of the longitudinal strain, under CF of $30 \mathrm{kN}$, about $5 \%$ of longitudinal strain on shrink flange occurs. As it approaches from flange to bottom center, the absolute value of the strain decreased. On the other hand, $7 \%$ of longitudinal strain on stretch flange occurs. And the same remark as the stretch side can be made. Under $\mathrm{CF}$ of $500 \mathrm{kN}$, relatively about $3 \%$ of longitudinal strain on shrink side increased compared to that with $\mathrm{CF}$ of $30 \mathrm{kN}$, and relatively about $7 \%$ of longitudinal strain on stretch flange increased compared to that with $\mathrm{CF}$ of $30 \mathrm{kN}$.

Fig.14, and Fig.15 shows the variation of curvature, under $\mathrm{CF}$ of $30 \mathrm{kN}$, about $0.005 \mathrm{~mm}^{-1}$ of curvature in section 1 occurs, and about $0.003 \mathrm{~mm}^{-1}$ of curvature in section 5 oocurs. Under CF of $500 \mathrm{kN}, 0.002 \mathrm{~mm}^{-1}$ of curvature in section 5 on shrink side is decreased relatively, and about $0.003 \mathrm{~mm}^{-1}$ on stretch side is decreased.

Under the influence of high CF, strain in the longitudinal direction increased $5 \sim 7 \%$. And it can be said that the amount of curvature decreased as tension increased in the vertical direction. But twist did not vary.

The results obtained in this section can be summarized that under higher $\mathrm{CF}$ of $500 \mathrm{kN}$, the amount of the longitudinal strain increased. However twist did not vary relatively. Hence, the cushion force had almost no relation to twist.

\section{MECHANISM OF OCCURRING TWIST AND STRATEGY TO DECREASE}

4.1 Deformation behavior by slitting flange and side wall

By slitting flanges and side wall to release the residual stress and moment, the influence of these on twist was investigated. Relation between curvature and twist are shown.

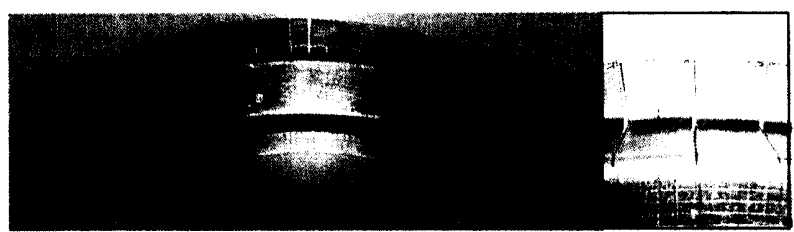

Fig.16 Slit off flange and side wall

As shown in Fig.16, 17 sections were slit off. Firstly, shrink flange was slit off, and then side wall on shrink side is slit off. And the same way as the stretch side is taken. Fig.17 shows the variation of curvature, before slitting, about $0.006 \mathrm{~mm}^{-1}$ of curvature in section 1 occurred, and about $0.003 \mathrm{~mm}^{-1}$ of curvature in section 5 occurred. By slitting shrink flange, curvature varied little 
relatively. And slitting side wall on shrink side, about $0.004 \mathrm{~mm}^{-1}$ of curvature occurred, when the residual moment was released. Curvature on stretch side did not vary by slitting product.

Fig-18 shows the variation of twist, before slitting, 4 degrees of twist in section 1 had been occurred. By slitting shrink flange, 3 degrees of twist in section 1 occurred, and by slitting side wall on shrink side, 1 degree of twist occurred.

Fig.19 shows the variation of curvature, before slitting, about $0.006 \mathrm{~mm}^{-1}$ of curvature in section 1 occurred, and about $0.003 \mathrm{~mm}^{-1}$ of curvature in section 5 occurred. By slitting stretch flange, curvature varied little. And slitting side wall on stretch side, about $0.004 \mathrm{~mm}^{-1}$ of curvature occurred, when the residual moment was released. Curvature on shrink side does not change by slitting the product.

Fig.20 shows the variation of twist, before slitting, 4 degrees of twist in section 1 have been occurred. By slitting stretch flange, twist did not vary, and by slitting side wall on stretch side, 5 degrees of twist in section 1 occurred.

It is observed that the residual moment plays an important role on twist.

\subsection{Mechanism of occurring twist}

Experiment results show that twist does not occur in straight product. 0.7 and 2.0 degrees of twist occur in section 3 in curved product and combined product, respectively. This increase of the amount of twist in the combined part can be considered as the result of the connection of curved part with straight part.

The residual moment is released by slitting side wall on shrink side, and side wall is opened outward owing to spring back. And simultaneously twist angle is decreased.

When side wall is opened owing to spring back, the circumferential length is varied, as shown in Fig.21.On shrink side, the circumferential length increases, and on stretch side it decreases. But the extensional deformation does not occur on shrink side, and the compressible deformation does not occur on stretch side. Hence, displacement occurs from A to B on shrink side, and

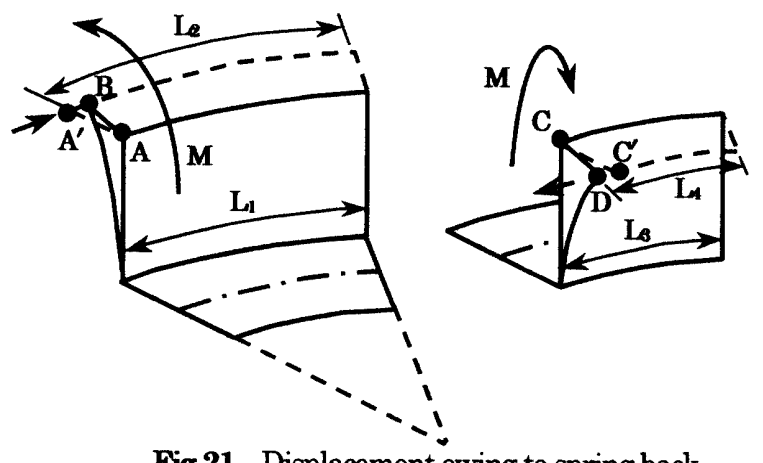

Fig.21 Displacement owing to spring back

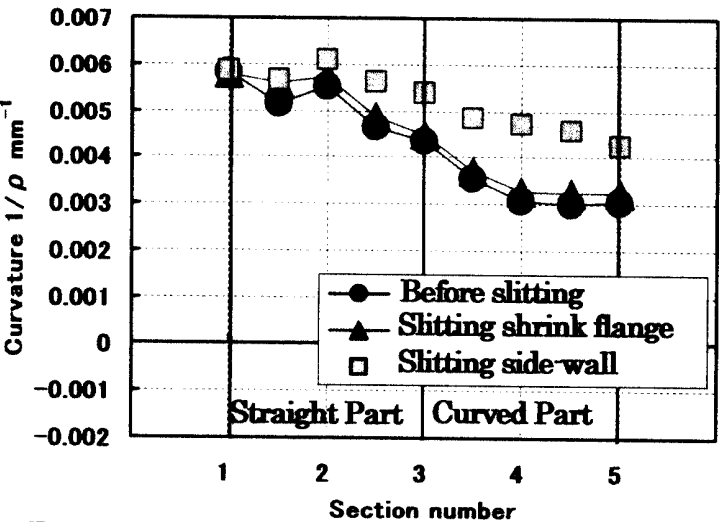

Fig.17 Distribution of curvature, slitting shrink side

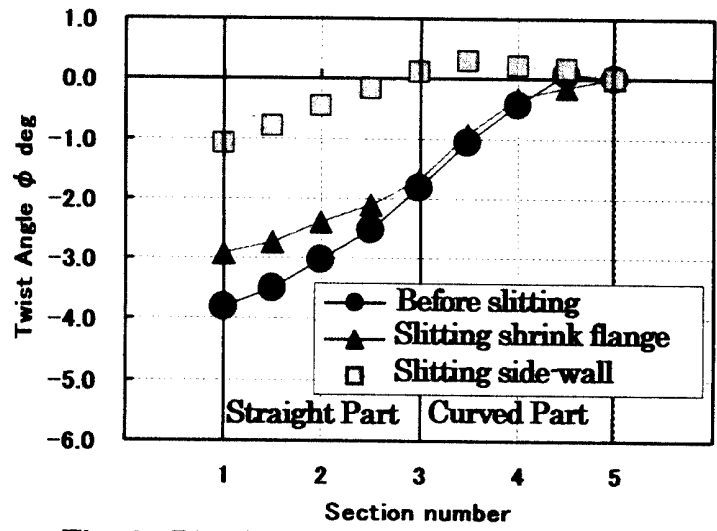

Fig.18 Distribution of twist, slitting shrink side

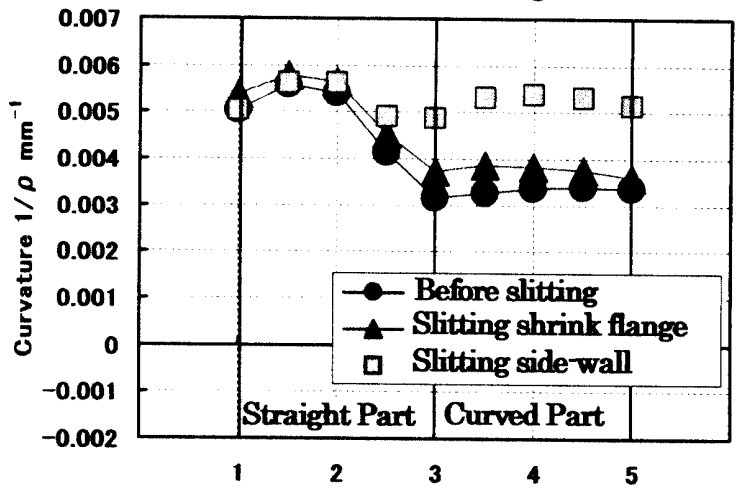

Fig.19 Distribution of curvature, slitting stretch side

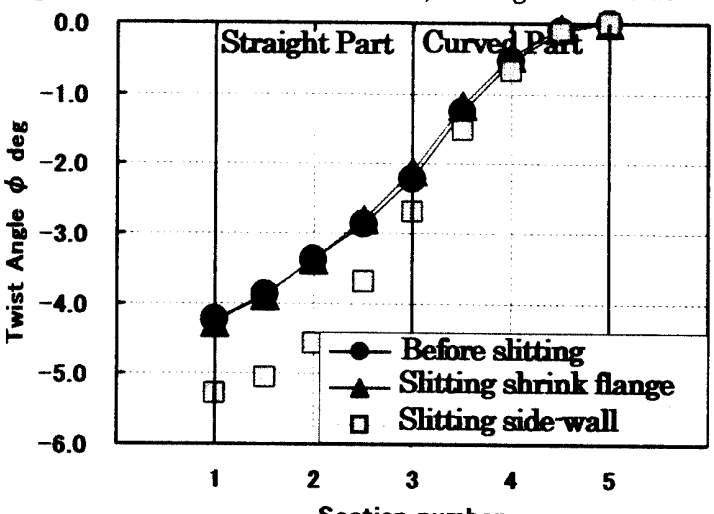

Fig.20 Distribution of twist, sylttang stretch side 
displacement occurs from $\mathrm{C}$ to $\mathrm{D}$ on stretch side as shown in Fig.21. It can be considered that the displacement of both shrink side and stretch side makes twist .

\subsection{Strategy to decrease twist quantity}

Aiming to decrease the residual moment which cause spring back, the new die, which includes $2 \mathrm{~mm}$ of die radius in longitudinal direction, is set up as shown in Fig.22. $2 \mathrm{~mm}$ of die radius is set from section 1 to section 3 on shrink side, and from section 3 to section 5 on stretch side. This die radius increased from $2 \mathrm{~mm}$ to 6 mm smoothly. Relation between curvature and twist on all sections are compared with new die and conventional die.

Fig.23, and Fig.24 shows the variation of curvature, about $0.006 \mathrm{~mm}^{-1}$ of curvature occurs in section 1 , and about $0.003 \mathrm{~mm}^{-1}$ of curvature occurs in section 5 on both shrink side and stretch side with the conventional die.

As shown in Fig.23 on the shrink side, about $-0.002 \mathrm{~mm}^{-1}$ of curvature occurs in section 1 , and about $0.002 \mathrm{~mm}^{-1}$ of curvature occurs in section 5 with the new die.

As shown in Fig.24 on the stretch side, about $0.004 \mathrm{~mm}^{-1}$ of curvature occurs in section 1 , and about $-0.001 \mathrm{~mm}^{-1}$ of curvature occurs in section 5 with the new die.

As a result, twist is decreased from 4 degrees to 1 degree, as shown in Fig.25.

Based on the above, the side wall is opened less than that with conventional die, if the residual moment is decreased. Then twist is decreased.

\section{CONCLUSION}

When a hat channel product combining straight part with curved part, twist in the longitudinal direction occurs. The factors in twisting are investigated.

(1) By varying the blank holding force and cushion force, the amount of the longitudinal strain increased about $5 \%$ relatively. However twist varied little. Hence, the blank holding force and the cushion force have almost no relation to twist.

(2) By slitting flanges and side wall to release the residual stress and moment, 3 degrees of twist decreased. Hence, the residual moment plays an important role in twist.

(3) Aiming to decrease the residual moment, $2 \mathrm{~mm}$ of die radius was set up at section 1 on shrink side and at section 5 on stretch side. Side wall opens less, if the residual moment decreases. As a result, twist was decreased by 3 degrees.

\section{REFERENCE}

[1] Asakawa, M., Abe, T., Nishikiori, S., Hama, T., Kuwayama, I., Fujishiro, Y., Hayashi, I. :Optimum forming condition of Box-shaped cross section products, J.

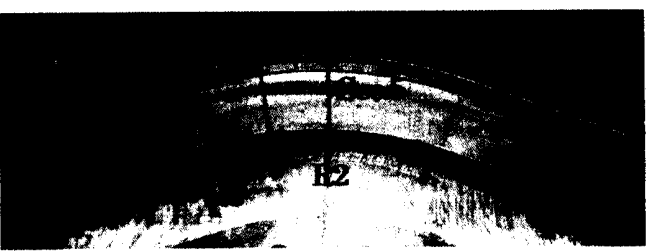

Fig.22 The new die which includes $2 \mathrm{~mm}$

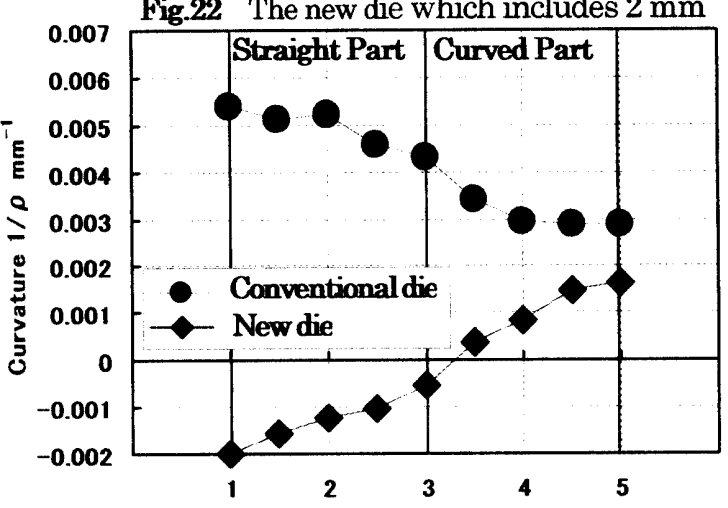

Fig.23 Distribution of curvature (shrink side)

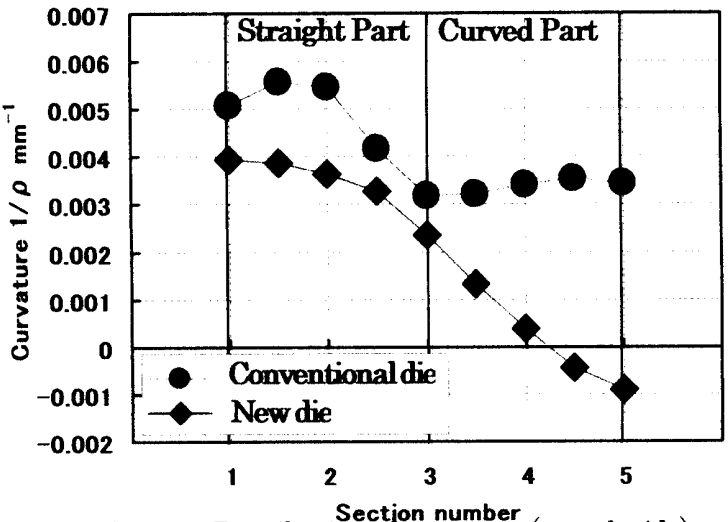

Fig.24 Distribution of curvature (stretch side)

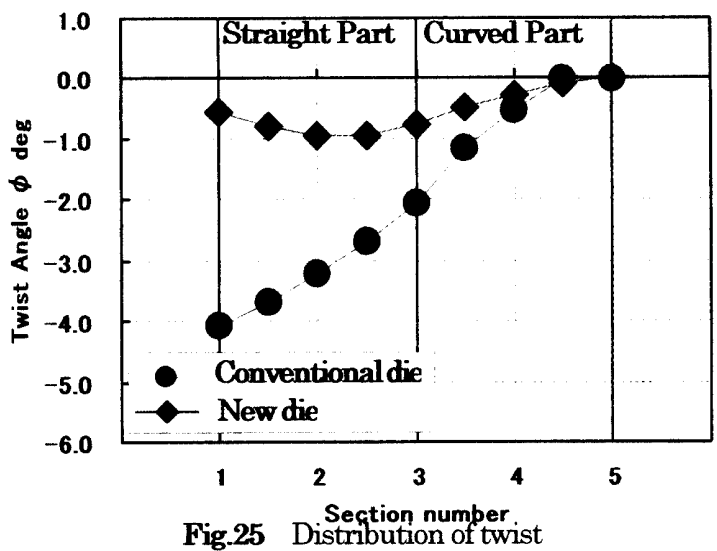

of the Japan Society for Technology of Plasticity, Vol.42 no.486 (2001),720-724 (in Japanese)

[2] Sudo, C., :Investigation of torsional growth after press forming of thin steel sheets, J. of the Japan Society for Technology of Plasticity, Vol.17 no.189 (1976), 783-790 (in Japanese) 